\title{
A silent public health threat: emergence of Mayaro virus and co-infection with Dengue in Peru
}

\author{
Miguel Angel Aguilar-Luis ${ }^{1,2+}$, Juana del Valle-Mendoza ${ }^{1,2^{*}+}$ (0), Isabel Sandoval ${ }^{3}$, Wilmer Silva-Caso ${ }^{1,2}$, \\ Fernando Mazulis ${ }^{1}$, Hugo Carrillo-Ng ${ }^{1,2}$, Yordi Tarazona-Castro ${ }^{1,4}$, Johanna Martins-Luna ${ }^{1,2}$, \\ Ronald Aquino-Ortega ${ }^{1,2}$, Isaac Peña-Tuesta ${ }^{1,2}$, Angela Cornejo-Tapia ${ }^{1}$ and Luis J. del Valle ${ }^{5^{*}}$
}

\begin{abstract}
Objective: To describe frequency and clinical characteristics of MAYV infection in Piura, as well as the association of this pathogen with DENV.

Results: A total of 86/496 (17.3\%) cases of MAYV were detected, of which 54 were MAYV mono-infection and 32 were co-infection with DENV, accounting for $10.9 \%$ and $6.4 \%$, respectively. When evaluating monoinfection by MAYV the main groups were $18-39$ and $40-59$ years old, with $25.9 \%$ and $20.4 \%$ respectively. Co-infections were more common in the age group $18-39$ and those $>60$ years old, with $34.4 \%$ and $21.9 \%$, respectively. The most frequent clinical presentation were headaches $(94.4 \%, 51 / 54)$ followed by arthralgias $(77.8 \%, 42 / 54)$. During the 8 -month study period the most cases were identified in the months of May (29.1\%) and June (50.0\%).
\end{abstract}

Keywords: Arbovirus, Alphavirus, Mayaro virus, Dengue, PCR, Peru

\section{Introduction}

Mayaro virus (MAYV) infection is a neglected tropical disease that represents an important cause of acute febrile illness (AFI) in endemic areas. In 2019, PAHO declared an epidemiological alert due to the recent increase in outbreaks and the potential of this pathogen to become a significant public health issue [1]. The virus was first isolated from 5 patients in Trinidad and Tobago during the outbreak in the county of Mayaro in 1954 [2]. Outbreaks throughout the South American

\footnotetext{
*Correspondence: juana.delvalle@upc.pe; luis.javier.del.valle@upc.edu ${ }^{\dagger}$ Miguel Angel Aguilar-Luis and Juana del Valle-Mendoza contributed equally to this article

1 School of Medicine, Research and Innovation Center of the Faculty of Health Sciences, Universidad Peruana de Ciencias Aplicadas, Lima, Peru

${ }^{5}$ Barcelona Research Center for Multiscale Science and Engineering, Departament D’Enginyeria Química, EEBE, Universitat Politècnica de Catalunya (UPC), Barcelona, Spain

Full list of author information is available at the end of the article
}

amazon basin have been reported [3], as well as imported cases in Europe [4].

MAYV is a positive-sense single-stranded RNA virus of the Alphavirus genus [4]. This group is composed of seven viruses, which share common antigenic sites: Bebaru virus, Chikungunya virus, Getah virus, Semliki Forest virus, Ross River virus, O'nyong-nyong virus, and UNA virus. The antigenic similarities between these viruses have previously shown cross-reactivity in serological tests [5-7]; for this reason molecular assays are required for a precise diagnosis [8].

The first case of MAYV in Peru was reported in 1999 by Tesh et al. [9], and multiple outbreaks have been reported in the Peruvian territory throughout the years [10-12]. Peru has the 2nd highest number of cases reported in Latin America according to academic literature with 230 confirmed cases, following Brazil with 495 cases [13]. However, it is important to note that previous studies have shown that the real disease 
burden may be underestimated due to underreporting and misdiagnosis [14].

Alphavirus infections are mainly characterized by a broad range of non-specific signs and symptoms including fever, headache, rash, myalgias, among others [5, $14,15]$. However, Semliki group alphaviruses have been associated with arthralgias [16] and persistent incapacitating joint pain due to MAYV infection has been previously reported in a series of imported cases [17-19]. Accurate clinical differentiation between arbovirus and MAYV is a challenge for clinicians in endemic areas [20]; however, without sensitive and specific diagnostic tools, a precise etiological diagnosis cannot be easily achieved $[14,21]$.

A topic of great interest is the association between MAYV infection with other arboviruses, particularly Dengue virus (DENV). Sporadic cases of co-infection between MAYV and DENV have been previously reported [18, 22, 23]. However, several issues remain unanswered regarding the clinical presentation of coinfections between these pathogens. For example, it has not yet been characterized if co-infections exhibit a more specific clinical presentation or more severe symptoms. Furthermore, it has not been determined if co-infections suggest evidence of a shared vector.

Non-human primates play an important role as reservoirs for MAYV, maintaining the zoonotic cycle in the rainforest. [24]. Even though enzootic cycles are not fully characterized, canopy dwelling mosquitoes of the genus haemagogus are considered the main vectors [2527]. Izurieta et al. [27] proposed that Haemagogus spp. was responsible for the sylvatic cycle of virus transmission and people living or working in the peri-urban area or forest peripheries, would provide the bridge to the urban setting.

The degree to which MAYV is adapted to infect more anthropophilic urban mosquitoes such as A. aegypti, Ae. albopticus and Ae. scapularis has only been evidenced in laboratories [28, 29]. However, single amino acid mutations in alphaviruses have been shown to improve adaption to mosquito species that are not normally considered the primary vector [30]. Consequently, MAYV urbanization poses an important risk to become a significant public health issue with the potential for epidemics in the same way CHIKV evolved over the years [31]. Our aim is described the frequency and clinical characteristics of MAYV infection in Piura, as well as the association of this pathogen with DENV.

\section{Main text \\ Methods \\ Study location}

A consecutive cross-sectional study was performed in six primary heath care centers between February and September of 2016 in the district of Morropon, Piura (Additional file 1: Figure S1). The department of Piura is located in the northern coast of Peru sharing boundaries with Ecuador to the north. It has a population of $1,856,809$ (the second larger in Peru), with $79.3 \%$ in urban areas and $20.7 \%$ in rural areas, according to the last national census. This region is endemic for different pathogens responsible for AFI such as DENV, leptospirosis, among others.

\section{Study subjects}

Patients were recruited in the context of the syndromic surveillance program between February and September of 2016. All patients with a suspected AFI who attended the healthcare facilities within 7 days since the onset of quantified or not quantified patient-reported fever, were included. Patients with a temperature greater than $38{ }^{\circ} \mathrm{C}$ for $<7$ days without an identifiable source of infection and associated with one or more of the following signs and symptoms were included: headache, myalgia, arthralgia, retro-ocular pain, lower back pain, rash, hyperoxia, odynophagia, nausea, emesis, abdominal pain, asthenia, syncope, hypothermia, jaundice, and others. The exclusion criteria were patients with an incomplete medical record and patients with an identifiable source of infection, such as acute upper respiratory tract infections, pneumonia, and urinary tract infections, among others.

\section{Ethics statement}

The study protocol was approved by the Research Ethics Board of the Hospital Regional Docente de Cajamarca, Peru. The samples were obtained in the context of the epidemiological/syndromic surveillance program according to the health directives of the National Center for Epidemiology, Disease Control and Prevention of the Ministry of Health of Peru. Therefore, it was exempt from informed consent.

\section{Samples}

A total of 496 samples were collected using Vacuette TUBE Serum Separator Clot Activator (Vacuette; Greiner Bio-One, Kremsmünster, Austria). All the samples were stored at $-80^{\circ} \mathrm{C}$ after collection for molecular assays. 
Real-time reverse transcriptase PCR amplification for the detection of MAYV and DENV

RNA extraction was performed using the High Pure RNA Isolation Kit (Roche Applied Science, Mannheim, Germany) following the manufacturer's instructions; $200 \mu \mathrm{l}$ of the serum samples was used. The viral RNA obtained was stored at $-80{ }^{\circ} \mathrm{C}$ until use.

Amplification by Real-time RT-PCR assay for the detection of MAYV was carried out using the primers and PCR conditions described by Aguilar-Luis et al. [32]. Amplification by Real-time RT-PCR assay for DENV was described by Leparc-Goffart et al. [33], and the PCR conditions were described by Alva-Urcia et al. [14].

\section{Statistical analysis}

Qualitative variables were reported as frequencies and percentages. Chi square test was performed to estimate statistical association between the variables, a value of $\mathrm{p}<0.05$ was considered significant. All analyses were processed with the IBM Statistical Package for the Social Sciences (SPSS) software version 21.0 (SPSS, Chicago, IL, USA).

Maps were created using QGIS 3.12.3 software. Data for creating the map were acquired from the Instituto Nacional de Estadística e Informática (https://www.inei. gob.pe/).

\section{Results}

A total of 496 samples were collected during the study period. The detection of MAYV was performed with RT-PCR amplification of nsP1 for MAYV RNA. A total of $86 / 496(17.3 \%)$ cases of MAYV were detected by this assay and among these: 54 were MAYV mono-infection and 32 were co-infection with DENV, accounting for $10.9 \%$ and $6.4 \%$, respectively.
Table 1 summarizes the demographic characteristics of all the patients included in this study. The main age groups diagnosed with Mayaro virus were the patients between 18-39 and 40-59 years old, with 29.1\% and $18.6 \%$ respectively. When evaluating monoinfection by MAYV, the main groups were 18-39 and 40-59 years old, with $25.9 \%$ and $20.4 \%$ respectively. Co-infections were more common in the age group 18-39 and those $>60$ years old, with $34.4 \%$ and $21.9 \%$, respectively. No significant differences were found when evaluating monoinfection and co-infections and the demographic variables studied.

In regard to the clinical presentation, the most frequent symptom in MAYV infection were headaches (94.4\%, $51 / 54)$ followed by arthralgias $(77.8 \%, 42 / 54)$ (Table 2$)$.

Finally, an assessment of the monthly distribution of the MAYV cases detected during the 8-month period of study was performed (Fig. 1). During the 8-month study period the most cases were identified in the months of May (29.1\%) and June (50.0\%).

\section{Discussion}

An important number of cases of MAYV were detected in patients with AFI that attended outpatient healthcenters during this study. Approximately, a fifth of the total cases were diagnosed with MAYV, demonstrating that this pathogen may be circulating within the region and that peri-urban transmission may be ongoing. Moreover, approximately $6.4 \%$ of the total cases were co-infection between MAYV and DENV.

The association between MAYV and DENV is a topic of great interest for the scientific community, as both pathogens share common characteristics and can co-exist in a specific region. However, only two studies have previously reported co-infections of DENV

Table 1 Demographics in patients with arboreal acute febrile illness by MAYV and DENV

\begin{tabular}{|c|c|c|c|c|c|}
\hline \multirow[t]{2}{*}{ Characteristics } & \multirow{2}{*}{$\begin{array}{l}\text { Total cases } \\
n=496(\%)\end{array}$} & \multirow{2}{*}{$\begin{array}{l}\text { MAYV } \\
n=86(\%)\end{array}$} & \multicolumn{2}{|c|}{ Co-infections } & \multirow[t]{2}{*}{$p$ value* } \\
\hline & & & $\begin{array}{l}\text { Only MAYV } \\
n=54(\%)\end{array}$ & $\begin{array}{l}\text { DENV \& MAYV } \\
\mathrm{n}=32(\%)\end{array}$ & \\
\hline \multicolumn{6}{|l|}{ Age } \\
\hline$<5$ & $39(7.9)$ & $8(9.3)$ & $5(9.3)$ & $3(9.4)$ & 0.7097 \\
\hline $5-11$ & $68(13.7)$ & $12(14.0)$ & $8(14.8)$ & $4(12.5)$ & 0.7646 \\
\hline $12-17$ & $56(11.3)$ & $10(11.6)$ & $8(14.8)$ & $2(6.3)$ & 0.2311 \\
\hline $18-39$ & $146(29.4)$ & $25(29.1)$ & $14(25.9)$ & $11(34.4)$ & 0.4042 \\
\hline $40-59$ & $109(22.0)$ & 16 (18.6) & $11(20.4)$ & $5(15.6)$ & 0.5846 \\
\hline$\geq 60$ & $78(15.7)$ & $15(17.4)$ & $8(14.8)$ & $7(21.9)$ & 0.4043 \\
\hline \multicolumn{6}{|l|}{ Sex } \\
\hline Male & $226(45.6)$ & $43(50.0)$ & $30(55.6)$ & $13(40.6)$ & 0.1807 \\
\hline Female & $270(54.4)$ & $43(50.0)$ & $24(44.4)$ & $19(59.4)$ & 0.1807 \\
\hline
\end{tabular}

${ }^{*}$ Chi-square test was performed. $p$ value $<0.05$ was considered statistically significant 
Table 2 Clinical symptoms in patients with MAYV and DENV infection confirmed by PCR

\begin{tabular}{|c|c|c|c|c|}
\hline \multirow[t]{2}{*}{ Clinical symptoms } & \multirow{2}{*}{$\begin{array}{l}\text { Total cases } \\
n=496(\%)\end{array}$} & \multirow{2}{*}{$\begin{array}{l}\text { MAYV } \\
n=86(\%)\end{array}$} & \multicolumn{2}{|c|}{ Co-infections } \\
\hline & & & $\begin{array}{l}\text { Only MAYV } \\
n=54(\%)\end{array}$ & $\begin{array}{l}\text { DENV \& MAYV } \\
\mathrm{n}=32(\%)\end{array}$ \\
\hline Headache & $404(81.5)$ & $77(89.5)$ & $51(94.4)$ & $26(81.3)$ \\
\hline Arthralgia & $357(72.0)$ & $68(79.1)$ & $42(77.8)$ & $26(81.3)$ \\
\hline Myalgia & $378(76.2)$ & $68(79.1)$ & $41(75.9)$ & $27(84.4)$ \\
\hline Retro-ocular pain & $306(61.7)$ & $62(72.1)$ & $41(75.9)$ & $21(65.6)$ \\
\hline Hyporexia & $305(61.5)$ & $56(65.1)$ & $36(66.7)$ & $20(62.5)$ \\
\hline Lumbar pain & $246(49.6)$ & $45(52.3)$ & $29(53.7)$ & $16(50)$ \\
\hline Nausea/Emesis & $226(45.6)$ & $41(47.7)$ & $25(46.3)$ & $16(50)$ \\
\hline Odinophagia & $171(34.5)$ & $31(36.0)$ & $21(38.9)$ & $10(31.3)$ \\
\hline Rash & $81(16.3)$ & $11(12.8)$ & $6(11.1)$ & $5(15.6)$ \\
\hline Thrombocytopenia & $6(1.2)$ & $2(2.3)$ & $1(1.9)$ & $1(3.1)$ \\
\hline Chest pain/dyspnea & $20(4.0)$ & $2(2.3)$ & $2(3.7)$ & $0(0)$ \\
\hline Epistaxis & $8(1.6)$ & $2(2.3)$ & $2(3.7)$ & $0(0)$ \\
\hline Gingivorraghia & $3(0.6)$ & $2(2.3)$ & $1(1.9)$ & $1(3.1)$ \\
\hline Hematocrit increase & $5(1.0)$ & $2(2.3)$ & $1(1.9)$ & $1(3.1)$ \\
\hline Petechiae & $11(2.2)$ & $2(2.3)$ & $0(0)$ & $2(6.3)$ \\
\hline Lipothymia & $3(0.6)$ & $1(1.2)$ & $1(1.9)$ & $0(0)$ \\
\hline Sudden decrease in $T^{\circ}$ or hypothermia & $3(0.6)$ & $1(1.2)$ & $1(1.9)$ & $0(0)$ \\
\hline Cold Extremities / cyanosis & $2(0.4)$ & $1(1.2)$ & $1(1.9)$ & $0(0)$ \\
\hline Hypotension & $1(0.2)$ & $1(1.2)$ & $1(1.9)$ & $0(0)$ \\
\hline Conjunctival injection & $3(0.6)$ & $1(1.2)$ & $0(0)$ & $1(3.1)$ \\
\hline Weak pulse & $1(0.2)$ & $1(1.2)$ & $1(1.9)$ & $0(0)$ \\
\hline Cough & $1(0.2)$ & $1(1.2)$ & $0(0)$ & $1(3.1)$ \\
\hline Persistent vomiting & $5(1.0)$ & $1(1.2)$ & $1(1.9)$ & $0(0)$ \\
\hline BP differential < 20 MMHg & $1(0.2)$ & $0(0.0)$ & $0(0)$ & $0(0)$ \\
\hline Echimoses & $2(0.4)$ & $0(0.0)$ & $0(0)$ & $0(0)$ \\
\hline Shaking chills & $3(0.6)$ & $0(0.0)$ & $0(0)$ & $0(0)$ \\
\hline Hemoptysis & $1(0.2)$ & $0(0.0)$ & $0(0)$ & $0(0)$ \\
\hline Altered mental state & $1(0.2)$ & $0(0.0)$ & $0(0)$ & $0(0)$ \\
\hline Vaginal bleeding & $1(0.2)$ & $0(0.0)$ & $0(0)$ & $0(0)$ \\
\hline Hepatomegaly or jaundice & $1(0.2)$ & $0(0.0)$ & $0(0)$ & $0(0)$ \\
\hline Dizziness & $1(0.2)$ & $0(0.0)$ & $0(0)$ & $0(0)$ \\
\hline Melena & $2(0.4)$ & $0(0.0)$ & $0(0)$ & $0(0)$ \\
\hline
\end{tabular}

and MAYV in the scientific literature, a child with an unspecified febrile illness, serologically diagnosed with MAYV, [23], and during an outbreak in Brazil [22]. Our study reports the first clinical characterization of patients co-infected with MAYV and DENV near the Peruvian Amazon basin for eight months. The frequency of unspecific symptoms among patients with mono-infection and co-infeccion were similar, including fever, myalgia, arthralgia, retroorbital pain, and headache. This finding further confirms the majority of symptoms amongst arboviral infections are nonspecific, even when presenting as co-infections $[9,23$, $34-36]$.
Pinheiro et al. [35] previously reported that the rash associated with MAYV infection appears on the fifth day of illness, suggesting its association with of humoral antibody appearance. In contrast, we found patients with a rash on the 3rd day of illness for MAYV, second day for co-infected patients, and the first day for DENV mono-infected patients.

Serologic evaluations for the detection of alphaviruses have shown cross-reactivity [8] as they belong to the Semliki complex serologic group [6, 7], denoting the importance of sensitive and specific molecular diagnostic methods such as RT-PCR. Previous studies report that viremia is detectable for up to 5 days 


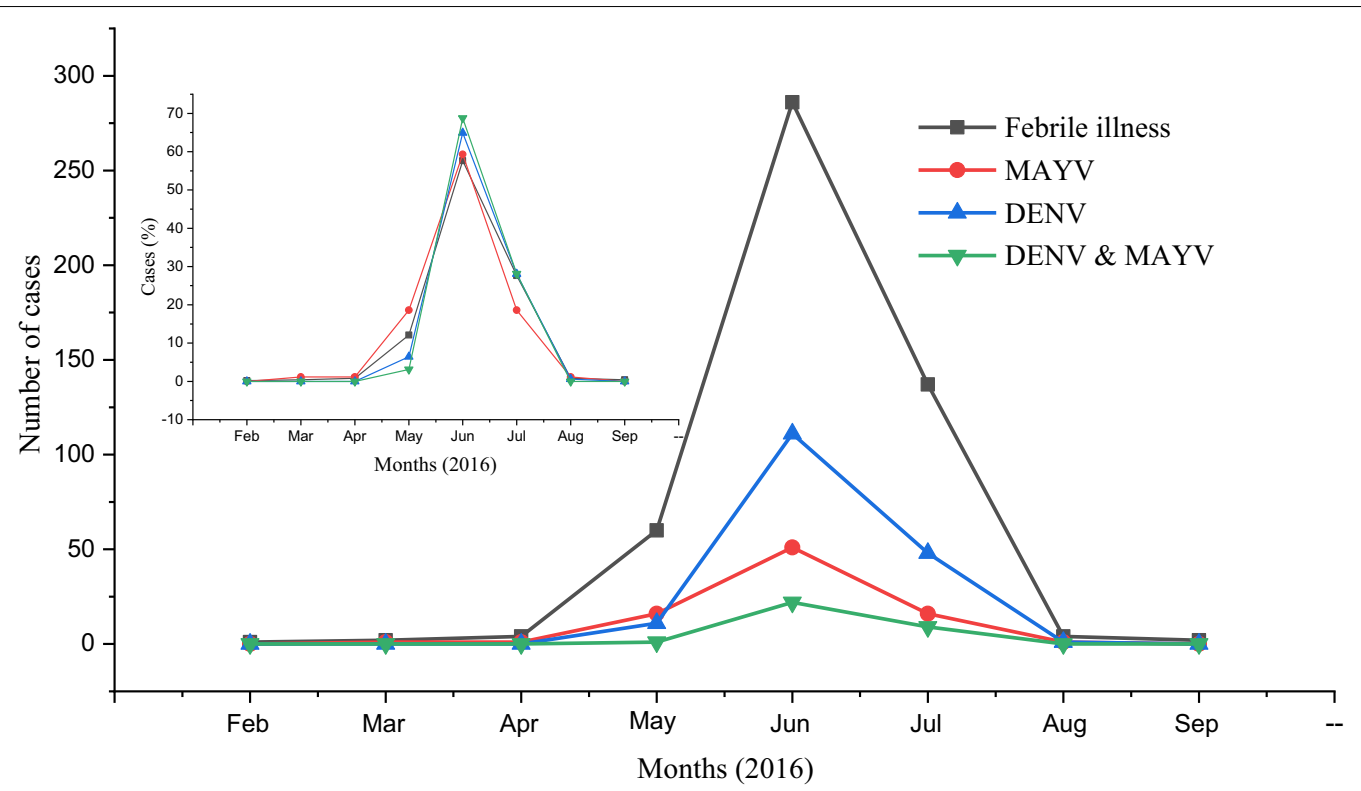

Fig. 1 Monthly distribution of the numbers of total cases of acute febrile illness and the numbers of MAYV, DENV, and MAYV \& DENV positive cases

post-infection [1]. However, we evidenced RT-PCR detection of MAYV up to 9 days in mono-infected patients and up to 7 days in co-infected patients. Our findings evidence that the window of detection for MAYV by RT-PCR could be longer than reported previously. Altogether, these characteristics make the RT-PCR an excellent diagnostic tool for the detection of MAYV during outbreaks.

Furthermore, our studied population showed no significant difference of positive cases between genders. A previous study determined that being male poses a risk for arboviral infections, given the higher occupational exposure [36]. Given that spillover zoonosis is considered the main source of recent arboviral outbreaks, this could have led to the peri-urban transmission of the disease [11]. Similarly, to our study, another outbreak in Brazil caused by peri-urban transmission of MAYV, showed that both genders were affected equally [22].

Additionally, we found a greater number of cases of both DENV and MAYV in May and July. This could be explained by some meteorological factors that could influence the vector expansion, behavior and biology. According to the meteorological national service (SENAMHI) the temperature and rainfall peak during the months of March and April; however, are still high during May and June, with a further decline in the later months. These factors altogether could enable a more easily transmission of the disease. Considering previous studies on the adaptability of alphaviruses to novel vectors [30], evidence of effective MAYV transmission by more urban anthropophilic mosquitoes in laboratory studies $[28,30$,
33], and high aedic index reported in the studied region (aedic index 1-4\%) [37], these findings may suggest that a common vector could be responsible for the transmission of both viruses during this outbreak. Further demographic and on-site vector studies are necessary to determine if the urbanization of MAYV is ongoing.

In conclusion, this study provides the first clinical characterization of patients co-infected with MAYV and DENV and also reports the first outbreak of MAYVDENV co-infections, confirmed by molecular diagnostic methods. Our findings also provide further evidence that symptoms in co-infected patients are non-specific and that disease severity may not be associated with co-infections.

\section{Limitations}

Some limitations of the study are that a majority of AFI cases could not be diagnosed with a precise etiology. Another limitation is that because of the design of the study, follow up could not be performed and longterm symptoms were not evaluated. Further, studies are required to better characterize the clinical picture and complications caused by co-infections between these two pathogens.

\section{Supplementary Information}

The online version contains supplementary material available at https://doi. org/10.1186/s13104-021-05444-8.

Additional file 1: Figure S1. Geographic distribution of co-infections and mono-infections of MAYV and DENV in the Morropon districts, Piura-Peru. 


\section{Abbreviations}

MAYV: Mayaro virus; DENV: Dengue virus; RT-PCR: Reverse transcription polymerase chain reaction; RNA: Ribonucleic acid; bp: Base pairs.

\section{Acknowledgments}

We thank the staff of the health network from la DIRESA Piura, Peru.

\section{Authors' contributions}

JdVM, LJdV, WSC and MAAL designed the study protocol. JdVM, MAAL, CPR. CTV, YTC, JML, IPT and ACT performed the PCR. JdVM, LJdV and MAAL were responsible for obtaining funding and laboratory work supervision. MAAL, IS, FM, HCN and RAO was responsible for the clinical assessment, samples collection and database completion. JdVM, WSC and LJdV were responsible to draft the manuscript. All authors critically revised the manuscript for intellectual content. All authors read and approved the final manuscript.

\section{Funding}

This work was supported by Incentives for Research of the Universidad Peruana de Ciencias Aplicadas, grant No UPC-A-058-2020, Lima-Peru. This research was supported by the Bio \& Medical Technology Development Program of the National Research Foundation (NRF) funded by the Korean government (MSIT) (No. 2015M3A9B6073666).

\section{Availability of data and materials}

Abstraction format used in the study and dataset are available and accessible from the corresponding author upon request in the link: https://figshare. $\mathrm{com} / \mathrm{s} / 03 f d 58 a c 3 f 5 c c 806629 f$.

\section{Ethics approval and consent to participate}

This study was approved by the Research Ethics Board of the Hospital Regional de Cajamarca, Peru. The samples were collected within the framework of the epidemiological surveillance program of febrile syndrome in the Cajamarca Region, so according to international ethical guidelines for research related to human health prepared by CIOMS and WHO, review is not required. Ethics or informed consent.

\section{Consent for publication}

Not applicable.

\section{Competing interests}

On behalf of all authors, the corresponding author states that there are no conflicts of interest or funding related to this study.

\section{Author details \\ ${ }^{1}$ School of Medicine, Research and Innovation Center of the Faculty of Health Sciences, Universidad Peruana de Ciencias Aplicadas, Lima, Peru. ${ }^{2}$ Laborato- rio de Biologia Molecular, Instituto de Investigación Nutricional, Lima, Peru. ${ }^{3}$ Subregión Morropon Huancabamba, Dirección Regional de Salud de Piura (DIRESA), Piura, Peru. ${ }^{4}$ Escuela Profesional de Genética Y Biotecnología. Facul- tad de Ciencias Biológicas, Universidad Nacional Mayor de San Marcos, Lima, Peru. ${ }^{5}$ Barcelona Research Center for Multiscale Science and Engineering, Departament D’Enginyeria Química, EEBE, Universitat Politècnica de Catalunya (UPC), Barcelona, Spain.}

Received: 12 October 2020 Accepted: 7 January 2021

Published online: 21 January 2021

\section{References}

1. Paho.org. Alerta Epidemiológica Fiebre De Mayaro; 2019. https://www. paho.org/sites/default/files/2019-06/2019-mayo-01-phe-alerta-epide miologica-mayaro.pdf. Accessed 13 July 2020.

2. Anderson CR, Downs WG, Wattley GH, Ahin NW, Reese AA. Mayaro virus: a new human disease agent. II. Isolation from blood of patients in Trinidad B.W.I. Am J Trop Med Hyg. 1957;6(6):1012-6.

3. Patiño-Barbosa AM, Bedoya-Arias JE, Cardona-Ospina JA, RodriguezMorales AJ. Bibliometric assessment of the scientific production of literature regarding Mayaro. J Infect Public Health. 2016;9(4):532-4.

4. Ganjian N, Riviere-Cinnamond A. Mayaro virus in Latin America and the Caribbean. Rev Panam Salud Publica. 2020;44:e14.
5. Acosta-Ampudia Y, Monsalve DM, Rodríguez Y, Pacheco Y, Anaya JM, Ramírez-Santana C. Mayaro: an emerging viral threat? Emerg Microbes Infect. 2018;7(1):163.

6. Hassing RJ, Leparc-Goffart I, Tolou H, van Doornum G, van Genderen PJ. Cross-reactivity of antibodies to viruses belonging to the Semliki forest serocomplex. Euro Surveill. 2010;15(23):19588.

7. Prat C, Flusin O, Panella A, Tenebray B, Lanciotti R, Leparc-Goffart I. Evaluation of commercially available serologic diagnostic tests for Chikungunya virus. Emerg Infect Dis. 2014;20(12):2129-32.

8. Fischer C, Bozza F, Merino Merino X, Pedroso C, de Oliveira FE, MoreiraSoto $A$, et al. Robustness of serologic investigations for chikungunya and mayaro viruses following coemergence. mSphere. 2020. https:// doi.org/10.1128/mSphere.00915-19.

9. Tesh RB, Watts DM, Russell KL, Damodaran C, Calampa C, Cabezas C, Ramirez G, Vasquez B, Hayes CG, Rossi CA, Powers AM, Hice CL, Chandler LJ, Cropp BC, Karabatsos N, Roehrig JT, Gubler DJ. Mayaro virus disease: an emerging mosquito-borne zoonosis in tropical South America. Clin Infect Dis. 1999;28(1):67-73.

10. Estudio interinstitucional desarrollado por las instituciones del Ministerio de Salud del Perú , en colaboración con el Instituto de Investigación de Enfermedades Tropicales de la Marina de los Estados Unidos, la Universidad Nacional Mayor de San Marcos, la Universidad Peruana Cayetano Heredia. Perfil etiológico del síndrome febril en áreas de alto riesgo de transmisión de enfermedades infecciosas de impacto en salud pública en el Perú, 2000-2001. Rev. perú. med. exp. salud publica. 2005;22(3): 165-174

11. Forshey B, Guevara C, Laguna-Torres V, Cespedes M, Vargas J, Gianella A, et al. Arboviral Etiologies of Acute Febrile Illnesses in Western South America, 2000-2007. PLoS Neglect Trop Dis. 2010;4(8):e787.

12. Halsey ES, Siles C, Guevara C, et al. Mayaro virus infection, Amazon Basin region, Peru, 2010-2013. Emerg Infect Dis. 2013;19(11):1839-42.

13. Ganjian N, Riviere-Cinnamond A. Mayaro virus in Latin America and the Caribbean. Revista Panamericana de Salud Pública. 2020:44:1.

14. Alva-Urcia C, Aguilar-Luis MA, Palomares-Reyes C, Silva-Caso W, SuarezOgnio L, Weilg P, Manrique C, Vasquez-Achaya F, Del Valle LJ, Del Valle-Mendoza J. Emerging and reemerging arboviruses: a new threat in Eastern Peru. PLoS ONE. 2017;12(11):e0187897.

15. Esposito DLA, Fonseca BA. Will Mayaro virus be responsible for the next outbreak of an arthropod-borne virus in Brazil? Braz J Infect Dis. 2017;21(5):540-4.

16. Levi L, Vignuzzi M. Arthritogenic Alphaviruses: A Worldwide Emerging Threat? Microorganisms. 2019;7(5):133.

17. de Thoisy B, Gardon J, Salas R, Morvan J, Kazanji M. Mayaro virus in wild mammals, French Guiana. Emerg Infect Dis. 2003;9(10):1326-9.

18. Karbaat J, Jonkers AH, Spence I. Arbovirus infections in Dutch military personnel stationed in Surinam: a preliminary study. Trop Geogr Med. 1964;16:370-6.

19. Hassing R, Leparc-Goffart I, Blank S, Thevarayan S, Tolou H, van Doornum $G$, et al. Imported Mayaro virus infection in the Netherlands. J Infect. 2010;61(4):343-5.

20. Paniz-Mondolfi A, Rodriguez-Morales A, Blohm G, Marquez M, VillamilGomez W. ChikDenMaZika syndrome: the challenge of diagnosing arboviral infections in the midst of concurrent epidemics. Ann Clin Microbiol Antimicrob. 2016;15(1):42.

21. Silva-Caso W, Aguilar-Luis MA, Palomares-Reyes C, Mazulis F, Weilg C, Del Valle LJ, Espejo-Evaristo J, Soto-Febres F, Martins-Luna J, Del Valle-Mendoza J. First outbreak of Oropouche Fever reported in a nonendemic western region of the Peruvian Amazon: molecular diagnosis and clinical characteristics. Int J Infect Dis. 2019;83:139-44.

22. Zuchi N, Heinen L, Santos M, Pereira F, Slhessarenko R. Molecular detection of Mayaro virus during a dengue outbreak in the state of Mato Grosso, Central-West Brazil. Memórias do Instituto Oswaldo Cruz. 2014;109(6):820-3.

23. Lednicky J, De Rochars V, Elbadry M, Loeb J, Telisma T, Chavannes S, et al. Mayaro virus in child with acute febrile illness, Haiti, 2015. Emerg Infect Dis. 2016:22(11):2000-2.

24. Neumayr A, Gabriel M, Fritz J, Günther S, Hatz C, Schmidt-Chanasit J, et al. Mayaro virus infection in traveler returning from amazon basin, Northern Peru. Emerg Infect Dis. 2012;18(4):695-6. 
25. Powers A, Chandler L, Tesh R, Russell K, Watts D, da Rosa A, et al. Genetic relationships among mayaro and una viruses suggest distinct patterns of transmission. Am J Trop Med Hyg. 2006;75(3):461-9.

26. Hoch A, LeDuc J, Pinheiro F, Peterson N. An Outbreak of Mayaro Virus Disease in Belterra, Brazil. Am J Trop Med Hyg. 1981;30(3):689-98.

27. Izurieta RO, DeLacure DA, Izurieta A, Hoare IA, Reina OM. Mayaro virus: the jungle flu. Virus Adapt Treat. 2018;10:9-17.

28. Moore C. Aedes albopictus in the United States: Ten-Year Presence and Public Health Implications. Emerg Infect Dis. 1997;3(3):329-34.

29. Long K, Tesh R, Higgs S, Hausser N, Thangamani S, Kochel T, et al. Experimental Transmission of Mayaro Virus by Aedes aegypti. Am J Trop Med Hyg. 2011;85(4):750-7.

30. Tsetsarkin K, Vanlandingham D, McGee C, Higgs S. A Single Mutation in Chikungunya virus affects vector specificity and epidemic potential. PLoS Pathog. 2007;3(12):e201.

31. Mackay I, Arden K. Mayaro virus: a forest virus primed for a trip to the city? Microbes Infect. 2016;18(12):724-34

32. Leparc-Goffart I, Baragatti M, Temmam S, Tuiskunen A, et al. Development and validation of real-time one-step reverse transcription-PCR for the detection and typing of dengue viruses. J Clin Virol. 2009;45(1):61-6.

33. Aguilar-Luis MA, Del Valle-Mendoza J, Silva-Caso W, Gil-RamirezT, Levy-Blitchtein S, Bazán-Mayra J, Zavaleta-Gavidia V, Cornejo-Pacherres
D, Palomares-Reyes C, Del Valle LJ. An emerging public health threat: Mayaro virus increases its distribution in Peru. Int $J$ Infect Dis. 2020:92:253-8.

34. Tesh RB. Arthritides caused by mosquito-borne viruses. Annu Rev Med. 1982;33:31-40.

35. Pinheiro F, Freitas R, da Rosa J, LeDuc J, Gabbay Y, Mello W. An Outbreak of Mayaro Virus Disease in Belterra, Brazil. Am J Trop Med Hyg. 1981;30(3):674-81.

36. Kreuder Johnson C, Hitchens P, Smiley Evans T, Goldstein T, Thomas K, Clements A, et al. Spillover and pandemic properties of zoonotic viruses with high host plasticity. Sci Rep. 2015;5(1):14830.

37. Sala de Situación de Salud - Semana Epidemiológica Nº 112017 (Internet). Lima: Centro Nacional de Epidemiología, Prevención y Control de Enfermedades - Ministerio de Salud; 2017. http://www.dge.gob.pe/porta l/docs/vigilancia/sala/2016/salaSE52.pdf. Accessed 19 July 2020

\section{Publisher's Note}

Springer Nature remains neutral with regard to jurisdictional claims in published maps and institutional affiliations.
Ready to submit your research? Choose BMC and benefit from:

- fast, convenient online submission

- thorough peer review by experienced researchers in your field

- rapid publication on acceptance

- support for research data, including large and complex data types

- gold Open Access which fosters wider collaboration and increased citations

- maximum visibility for your research: over $100 \mathrm{M}$ website views per year

At BMC, research is always in progress.

Learn more biomedcentral.com/submissions 